\title{
'MAK-10': A Long Shelf-life Charentais Breeding Line Developed by Introgression of a Genomic Region from Makuwa Melon
}

\author{
Gorka Perpiñá, Jaime Cebolla-Cornejo, and Cristina Esteras \\ Instituto de Conservación y Mejora de la Agrodiversidad Valenciana \\ (COMAV), Universitat Politècnica de València (UPV), Camino de Vera \\ 14, 46022 Valencia, Spain
}

\begin{abstract}
Antonio J. Monforte
Instituto de Biología Molecular y Celular de Plantas (IBMCP), Consejo Superior de Investigaciones Cientificas (CSIC), Universitat Politècnica de València (UPV), Camino de Vera s/n, 46022 Valencia, Spain
\end{abstract}

\section{Belén Picó ${ }^{1}$}

Instituto de Conservación y Mejora de la Agrodiversidad Valenciana (COMAV), Universitat Politècnica de València (UPV), Camino de Vera 14, 46022 Valencia, Spain

Additional index words. ripening behavior, flesh firmness, climacteric, cantaloupe, sugars content

'MAK-10' is a new breeding line derived from a collection of introgression lines (ILs) developed from the cross between the Japanese cultivar 'Ginsen makuwa' PI 420176 (Cucumis melo Group Makuwa) and the French cantaloupe variety 'Vedrantais' $(C$. melo Group Cantalupensis, Charentais type). 'MAK-10' and 'Vedrantais' do not differ in traits related to flowering and fruit morphology. However, 'MAK-10' fruits present a delayed ripening process, lacking abscission layer (AL) and external aroma. These changes in ripening provide fruits with delayed flesh softening and a higher sugar content, both while attached to the plant and after harvesting. These characteristics make 'MAK-10' useful to extend the harvesting period and the shelf life of Charentais melons.

Melon (C. melo L.) is a highly polymorphic cucurbit (Esteras et al., 2012; Pitrat, 2016). Intraspecific variation in many fruit traits has been described, including variation

\footnotetext{
Received for publication 1 May 2017. Accepted for publication 28 Aug. 2017.

This work has been carried out in the framework of the Programa de Valorización y Recursos Conjuntos de $\mathrm{I}+\mathrm{D}+\mathrm{i}$ de VLC/CAMPUS and has been funded by the Ministerio de Educación, Cultura y Deporte as part of the Programa Campus de Excelencia Internacional. IL generation, genotyping, and phenotyping were supported by SAFQIM project, AGL2012-40130-C02-02 of the Spanish Ministry of Economy and Competitivity (MINECO). We wish to thank the MINECO project AGL2014-53398-C2-2-R, co-funded with FEDER funds.
}

${ }^{1}$ Corresponding author. E-mail: mpicosi@btc.upv.es. in the ripening behavior, with a continuous spectrum from climacteric to nonclimacteric varieties (Ezura and Owino, 2008; Saladie et al., 2015). Climacteric melons, such as those of the Cantalupensis group, exhibit a sudden rise in respiration accompanied by an autocatalytic ethylene synthesis at the onset of the ripening (Pech et al., 2008), which is absent in nonclimacteric fruits.

Ripening behavior greatly affects fruit quality at harvest and during postharvest conservation (Rose et al., 1998; Saladie et al., 2015). Some of the processes that occur during the climacteric ripening, such as the formation of the $\mathrm{AL}$ and the synthesis of aroma volatiles, are ethylene dependent, whereas the sugar accumulation is ethyleneindependent, and both ethylene-dependent and independent flesh softening have been described (Pech et al., 2008).

There are many reports focused on the genetics of the melon fruit ripening process. The AL formation has been reported to be controlled by two duplicated independent loci (Al-3 and Al-4) located in chromosomes 8 and 9 (Perin et al., 2002). Additional QTLs involved in the ripening process have been found in chromosomes 1, 2, 3, 6, and 11 (Moreno et al., 2008; Vegas et al., 2013). Several genes acting in different steps of the ripening process have been cloned, such as those involved in the ethylene biosynthesis pathway [CmACS (1-aminocyclopropane-1carboxylate synthase) and the CmACO (1aminocyclopropane-1-carboxylate oxidase) genes], and orthologs of the main transcription factors involved in ethylene signaling (NAC transcription factor family and the HD-zip family) (Giovannoni, 2007; Lin et al., 2008; Saladie et al., 2015). In addition, genes associated with sugar accumulation and fruit softening have been identified that are differentially expressed between climacteric and nonclimacteric melons (Dai et al., 2011; Leida et al., 2015; Saladie et al., 2015; Zhang et al., 2016).

Many studies have been performed using cultivars with contrasting phenotypes for the ripening process, nonclimacteric (Inodorus group), and fully climacteric (Cantalupensis group) melons. In addition, the variability found in this trait in Asian melons (belonging to the Conomon or Makuwa groups) that have an intermediate ripening behavior (Guo et al., 2017) is also being explored (Moreno et al., 2008; Zhang et al., 2015).

Cantaloupe varieties are one of the melon market classes with the highest economic value. Two of the main objectives of cantaloupe breeding are to extend the harvesting period and the postharvest life maintaining fruit quality. Thus, the knowledge of the genetic basis of ripening behavior is essential for cantaloupe breeding programs. The modification of the ripening process in cantaloupe melons has been accomplished by silencing the CmACO1 gene (Ayub et al., 1996; Pech et al., 2008) and through the induction of mutations in this gene that provide an enhanced shelf life phenotype (DahmaniMardas et al., 2010).

In this report, we describe the ripening pre- and postharvest behavior of a melon breeding line ('MAK-10') obtained from a collection of ILs developed from the cross between a Japanese cultivar of the Makuwa group and the French cantaloupe variety 'Vedrantais' (Perpiñá et al., 2016). 'Vedrantais' represents one of the most important market classes of the Charentais type. It produces medium-size, global to flattened, sutured, and orange-fleshed fruits, with a full climacteric ripening behavior, aromatic, and with a medium sugar content. 'Ginsen makuwa' plants have an early female flowering, and their fruits are small and oval with a thin and smooth rind, and they have sweet white flesh with little aroma. They have a climacteric behavior intermediate between full climacteric and nonclimacteric melons (Leida et al., 2015; Saladie et al., 2015). Makuwa melons do not form a clear AL, whereas 'Vedrantais' melons drop off the plant when they reach a commercially ripe stage. The IL 'MAK-10' has an introgression in the chromosome 10 of the 'Ginsen makuwa' genome into the 'Vedrantais' genetic background (Perpiná et al., 2016). This introgression does not alter plant and fruit traits other than the ripening process. 'MAK10 ' fruits are morphological and organoleptically similar to 'Vedrantais' fruits, but lack $\mathrm{AL}$ and external aroma at full maturity. They maintain a higher flesh firmness (FF) and sugar content at maturity before and after harvesting. Therefore, 'MAK-10' may be an interesting source of genetic variability to develop new 'Vedrantais' cultivars with an improved postharvest life. 


\section{Origin}

The melon breeding line 'MAK-10' was obtained from an IL collection by introgressing the genome of 'Ginsen makuwa' PI 420176 (MAK) into the genetic background of the climacteric French 'Vedrantais' cultivar (VED) (Perpiñá et al., 2016). The whole IL collection was phenotyped in two locations: the greenhouse facilities of the Universitat Politècnica de València and of the Fundación Cajamar in Paiporta (lat. $39^{\circ} 25^{\prime}$ $2.208^{\prime \prime} \mathrm{N}$, long. $0^{\circ} 25^{\prime} 3,01^{\prime \prime} \mathrm{W}$ and altitude $17 \mathrm{~m}$ ) (both in Valencia, Spain) in three independent assays in which 'MAK-10' fruits showed an altered ripening phenotype, without AL, low external aroma, and higher FF, soluble solids, and sucrose content than VED fruits at commercial maturity. This line was selected from the $\mathrm{BC} 3 \mathrm{~S} 1$ generation after marker assisted selection using the Sequenom MassARRAY genotyping technology with Single Nucleotide Polymorphism (SNPs) evenly distributed through the genome. 'MAK-10' has a major MAK homozygous introgression of $1.05 \mathrm{Mb}$ located in chromosome 10 (between markers CMPSNP172 and CMPSNP65, Perpiñá et al., 2016) into the VED background, not shared with any other IL of the collection.

'MAK-10' BC3S1 plants were selfed to produce $\mathrm{BC} 3 \mathrm{~S} 2$ seeds. These seeds were used to perform a new characterization assay, aimed to confirm the effect of the introgression. Thirty plants of each VED and 'MAK-10' were cultivated in the greenhouse facilities of the Fundación Cajamar in Paiporta, in the spring-summer season in 2016 (from March to July). Plants were grown in substrate bags (70\% coconut fiber and 30\% coconut chips) and nutrients were provided through the irrigation system. Each plant was phenotyped for traits related to flowering (number of male and female flowers 15 and $30 \mathrm{~d}$ after the opening of the first female flower, coded NMaF15, NFeF15, NMaF30, and NFeF30). The plants were selfpollinated, and the fruits were sequentially harvested at different days after pollination (DAP), from 30 to 34 , from 35 to 39 , from 40 to 44 , from 45 to 49 , from 50 to 55 , and $>55$ DAP. In addition, fruits of the two genotypes collected at 40-44 and at 50-55 DAP were stored in a chamber at room temperature and phenotyped at 5 and $10 \mathrm{~d}$ after harvesting (DAH), with the aim to study the postharvest behavior. All the fruits were phenotyped for the following traits with the methodology described by Perpiñá et al. (2016): fruit weight (FW), fruit length and diameter (FL and FD), cavity width $(\mathrm{CW})$, flesh and rind thickness (Fth and Rth), FF, presence of AL, and netting occurrence (AL and NET), flesh color (FCHl, $\mathrm{FCa}, \mathrm{FCb}$ ), and soluble solids content (SSC). Sensory evaluation of the external aroma of the whole fruit was also performed, to determine if fruits have external aroma similar to that of VED of were nonaromatic as MAK (AR).

A cross section of $5 \mathrm{~cm}$ was obtained from the equatorial plane of each fruit. This sample was used for the quantification of sugars (sucrose, glucose, and fructose) and organic acids (citric, malic, and glutamic) via capillary electrophoresis with the methodology described by Cebolla-Cornejo et al. (2012) with an Agilent 7100 system (Agilent Technologies, Waldbronn, Germany). Results were expressed in grams per kilogram of fresh weight. Sucrose equivalents were calculated by multiplying sucrose, glucose, and fructose contents by their relative sweetening power, $1,0.74$ and 1.73 , respectively, and adding them up (Koehler and Kays, 1991).

\section{Description}

'MAK-10' and VED do not differ in flowering time and fruit morphology. 'MAK-10' and VED did not show differences in a number of traits related to flowering time and fruit morphology. Both lines flowered the same week after transplanting and had similar number of male (NMaF15 and NMaF30 were $3.90 \pm 0.57$ and $6.95 \pm 0.55$ vs. $4.11 \pm$ 0.25 and $7.10 \pm 0.39$ flowers, for 'MAK-10' and VED, respectively) and female (NFeF15 and $\mathrm{NFeF} 30$ were $2.66 \pm 0.24$ and $1.66 \pm 0.34$ vs. $2.21 \pm 0.16$ and $2.05 \pm 0.18$ ) flowers per plant, at 15 and $30 \mathrm{~d}$ after the opening of the first female flower.

'MAK-10' and VED fruits also did not differ in size and morphology during the ripening process, showing similar FW, FL, FD, CW, Fth and Rth, and rind netting at most DAP (Table 1). Therefore, despite the

Table 1. Mean and standard error of fruit weight (FW), fruit length (FL), fruit diameter (FD), cavity width (CW), rind thickness (Rth), flesh thickness (Fth), flesh firmness (FF), presence/absence of abscission layer (AL), aroma (AR) and netting (NET), soluble solids content (SSC), and flesh color (parameters FCH1, $\mathrm{FCa}, \mathrm{FCb}$ ) in 'Vedrantais' (VED) and 'MAK-10' fruits ${ }^{\mathrm{z}}$ collected at 30-34, 35-39, 40-44, 45-49, 50-55, and >55 d after pollination (DAP).

\begin{tabular}{|c|c|c|c|c|c|c|c|c|c|c|c|c|c|c|c|}
\hline \multirow[b]{2}{*}{ DAP } & \multirow[b]{2}{*}{ Genotype } & \multicolumn{2}{|c|}{ FW (g) } & \multicolumn{2}{|c|}{$\mathrm{FL}(\mathrm{mm})$} & \multicolumn{2}{|c|}{ FD (mm) } & \multicolumn{2}{|c|}{ CW (\%) } & \multicolumn{2}{|c|}{ Fth (mm) } & \multicolumn{2}{|c|}{ Rth (mm) } & \multicolumn{2}{|c|}{$\mathrm{FF}\left(\mathrm{kg} \cdot \mathrm{cm}^{-2}\right)$} \\
\hline & & Mean & SE & Mean & $\mathrm{SE}$ & $\overline{\text { Mear }}$ & $\overline{\mathrm{SE}}$ & Mean & $\mathrm{SE}$ & Mean & $\overline{\mathrm{SE}}$ & Mean & $\mathrm{SE}$ & Mean & $\mathrm{SE}$ \\
\hline \multirow[t]{2}{*}{$30-34$} & 'MAK-10' & 584.00 & 47.04 & 9.57 & 0.32 & 10.68 & 0.22 & 49.72 & 1.77 & 21.62 & 1.14 & 4.25 & 0.71 & 4.40 & 0.65 \\
\hline & VED & 616.37 & 52.87 & 9.80 & 0.32 & $10.5 \mathrm{C}$ & 0.28 & 48.70 & 1.81 & 21.14 & 0.95 & 5.44 & 0.37 & 6.60 & 0.71 \\
\hline \multirow[t]{2}{*}{$35-39$} & 'MAK-10' & 460.33 & 25.78 & 8.93 & 0.23 & 9.80 & 0.23 & 49.38 & 2.46 & 20.05 & 2.40 & $3.42 *$ & 0.12 & $3.40 *$ & 0.21 \\
\hline & VED & 580.00 & 103.24 & 9.46 & 0.40 & 10.52 & 0.67 & 50.47 & 4.16 & 22.98 & 3.14 & $4.70^{*}$ & 0.18 & $5.52 *$ & 0.24 \\
\hline \multirow[t]{2}{*}{$40-44$} & 'MAK-10' & 577.60 & 39.32 & 9.36 & 0.22 & 10.52 & 0.27 & 52.30 & 1.37 & 21.51 & 0.43 & 4.14 & 0.48 & 4.42 & 0.52 \\
\hline & VED & 534.11 & 32.25 & 9.48 & 0.17 & 10.17 & 0.22 & 49.16 & 0.85 & 21.61 & 1.13 & 3.77 & 0.21 & 3.57 & 0.21 \\
\hline \multirow[t]{2}{*}{$45-49$} & 'MAK-10’ & 476.25 & 27.57 & 8.70 & 0.17 & 10.10 & 0.17 & 50.64 & 2.72 & 19.65 & 1.08 & 4.20 & 0.42 & $4.27 *$ & 0.33 \\
\hline & VED & 498.00 & 32.99 & 9.04 & 0.25 & 9.99 & 0.21 & 48.18 & 1.18 & 20.61 & 0.80 & 3.68 & 0.42 & $2.36^{*}$ & 0.33 \\
\hline \multirow[t]{2}{*}{$50-55$} & 'MAK-10’ & 667.43 & 71.20 & 9.70 & 0.42 & 10.84 & 0.40 & $51.43^{*}$ & 2.42 & 23.97 & 1.28 & 3.45 & 0.37 & $3.28 *$ & 0.36 \\
\hline & VED & 498.20 & 24.40 & 8.56 & 0.26 & 9.62 & 0.31 & $43.29 *$ & 1.26 & 22.35 & 2.54 & 4.03 & 0.33 & $1.38^{*}$ & 0.32 \\
\hline \multirow[t]{3}{*}{$>55$} & 'MAK-10' & 492.00 & 106.00 & 8.75 & 0.15 & 10.4 & 0.60 & 45.88 & 2.75 & 26.3 & 1.36 & 3.40 & 0.10 & 5.00 & 0.10 \\
\hline & VED & - & - & - & - & - & - & - & 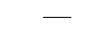 & - & - & - & - & - & - \\
\hline & & \multicolumn{2}{|c|}{$\mathrm{AL}^{\mathrm{y}}$} & \multicolumn{2}{|l|}{$\mathrm{AR}^{\mathrm{y}}$} & \multicolumn{2}{|c|}{$\mathrm{NET}^{\mathrm{y}}$} & \multicolumn{2}{|c|}{$\mathrm{FCHl}$} & \multicolumn{2}{|c|}{$\mathrm{FCa}$} & \multicolumn{2}{|c|}{$\mathrm{FCb}$} & \multicolumn{2}{|c|}{ SSC $\left({ }^{\circ}\right.$ Brix $)$} \\
\hline DAP & Genotype & Mean & $\overline{\mathrm{SE}}$ & Mean & $\overline{\mathrm{SE}}$ & Mean & $\overline{\mathrm{SE}}$ & Mean & $\overline{\mathrm{SE}}$ & Mean & $\overline{\mathrm{SE}}$ & Mean & $\mathrm{SE}$ & Mean & $\mathrm{SE}$ \\
\hline \multirow[t]{2}{*}{$30-34$} & 'MAK-10' & 0.00 & 0.00 & 0.00 & 0.00 & 1.00 & 0.00 & 64.15 & 2.97 & $-4.95 *$ & 0.76 & $19.58^{*}$ & 0.34 & 5.60 & 0.27 \\
\hline & VED & 0.00 & 0.00 & 0.00 & 0.00 & 0.75 & 0.16 & 55.59 & 2.82 & $4.42 *$ & 1.40 & $21.70 *$ & 0.48 & 6.58 & 0.35 \\
\hline \multirow[t]{2}{*}{$35-39$} & 'MAK-10' & 0.00 & 0.00 & 0.00 & 0.00 & 1.00 & 0.00 & 59.58 & 3.60 & 4.71 & 4.31 & 21.12 & 1.12 & 7.03 & 1.13 \\
\hline & VED & 0.00 & 0.00 & 0.00 & 0.00 & 0.80 & 0.20 & 66.19 & 3.36 & 6.17 & 1.65 & 23.72 & 0.51 & 7.40 & 0.97 \\
\hline \multirow[t]{2}{*}{$40-44$} & 'MAK-10' & 0.00 & 0.00 & 0.00 & 0.00 & 1.00 & 0.00 & $63.91^{*}$ & 0.98 & 6.47 & 1.96 & 23.80 & 1.05 & 9.64 & 1.14 \\
\hline & VED & 0.28 & 0.11 & 0.33 & 0.11 & 0.83 & 0.09 & $53.69 *$ & 1.55 & 6.97 & 1.44 & 22.43 & 0.55 & 11.21 & 0.62 \\
\hline \multirow[t]{2}{*}{$45-49$} & 'MAK-10' & $0.00 *$ & 0.00 & $0.00 *$ & 0.00 & 1.00 & 0.00 & 54.65 & 1.75 & 8.25 & 1.32 & 23.19 & 0.65 & 13.65 & 0.64 \\
\hline & VED & $1.00 *$ & 0.00 & $1.00 *$ & 0.00 & 1.00 & 0.00 & 56.56 & 2.81 & 9.90 & 0.53 & 24.08 & 1.03 & 13.08 & 0.91 \\
\hline \multirow[t]{2}{*}{$50-55$} & 'MAK-10' & $0.00 *$ & 0.00 & $0.00 *$ & 0.00 & 1.00 & 0.00 & 54.53 & 0.72 & $10.92 *$ & 0.46 & 23.25 & 0.49 & $15.68 *$ & 0.32 \\
\hline & VED & $1.00 *$ & 0.00 & $1.00 *$ & 0.00 & 1.00 & 0.00 & 49.48 & 3.62 & $6.84 *$ & 0.63 & 20.04 & 1.63 & $12.76^{*}$ & 0.64 \\
\hline$>55$ & 'MAK-10' & 0.00 & 0.00 & 0,00 & 0.00 & 1.00 & 0.00 & 54.38 & 1.08 & 12.60 & 1.30 & 24.48 & 0.00 & 15.90 & 0.30 \\
\hline & VED & - & - & - & - & - & - & - & - & - & - & - & - & - & - \\
\hline
\end{tabular}

${ }^{\mathrm{z}} \mathrm{Six}$ fruits of each DAP and genotype were phenotyped except for VED at $>55$ DAP (rotten fruits were not analyzed).

${ }^{\mathrm{y}} \mathrm{AL}, \mathrm{AR}$ and NET are abscission layer (1: present as in VED, 0:absent as in MAK), external aroma of the whole fruits (1: present as in VED, 0: absent as in MAK), netting (1: presence, 0: absence). All the other traits were evaluated as described in Perpiná et al. (2016).

*Significantly different based on the least significant difference test $(P \leq 0.05)$ between 'MAK-10' and VED. 
early flowering, the small fruit size, the oval shape, and the thin and smooth rind of the MAK fruits (Perpiña et al., 2016), the MAK introgression from chromosome 10 into the VED background of line 'MAK-10' did not alter these traits.

'MAK-10' differ from VED in the ripening process. One of the traits associated with the ripening process is FF. VED fruits presented a typical profile of FF evolution (Rose et al., 1998 ) with a continuous decrease of firmness (FF ranging from $6.60 \pm 0.71$ to $1.38 \pm 0.32$ $\mathrm{kg} \cdot \mathrm{cm}^{-2}$ at $30-34$ and $50-55$ DAP, respectively) (Fig. 1). However, the firmness of 'MAK-10' fruits remained constant during the ripening process ( $\mathrm{FF}$ of $4.40 \pm 0.65$ and $3.28 \pm 0.36 \mathrm{~kg} \cdot \mathrm{cm}^{-2}$ at $30-34$ and $50-55$ DAP).

VED fruits started to form the AL at 40 44 DAP and at 50-55 DAP most of the VED fruits had dropped from the plant and we could not harvest fruits after 55 DAP. 'MAK10 ' fruits did not form AL during the whole ripening process (Table 1 ), and even after 55

\section{Flesh firmness}

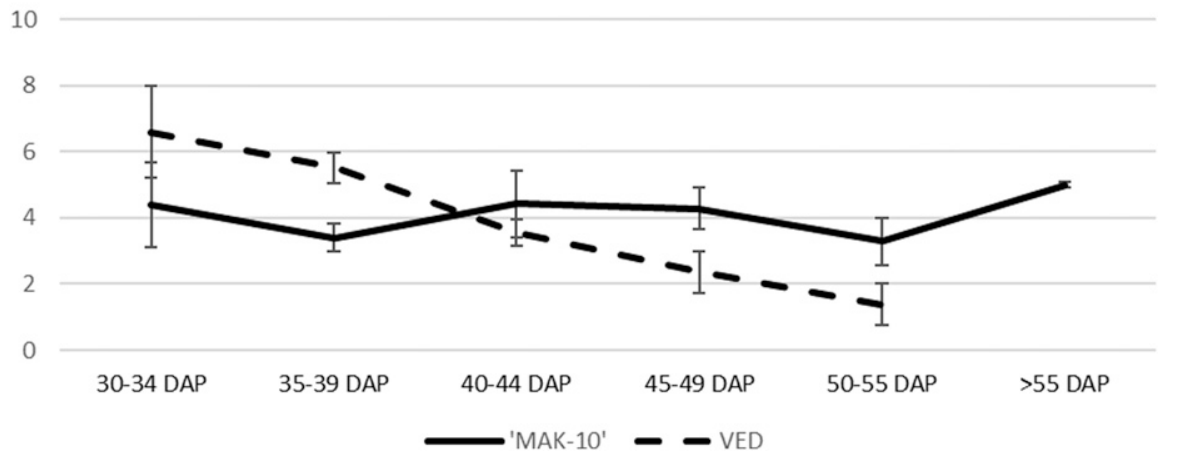

Fig. 1. Flesh firmness $\left(\mathrm{kg} \cdot \mathrm{cm}^{-2}\right)$ changes in fruits harvested at different days after pollination (DAP).
DAP, the fruits remained attached to the plant.

The formation of the AL is an external signal of maturity of climacteric fruits and is associated with the occurrence of external aroma. VED fruits reached full maturity from 40 to 49 DAP, exhibiting at this time appropriated FF and SSC, based on commercial standards (FF from $3.57 \pm 0.21$ to $2.36 \pm 0.33$ $0.91{ }^{\circ}$ Brix, at 40-44 and 45-49 DAP, respectively). VED fruits collected later, at 50 55 DAP were overripened, with very soft flesh (FF $1.38 \pm 0.32 \mathrm{~kg} \cdot \mathrm{cm}^{-2}$ ). 'MAK-10' fruits collected at the VED ripening time (from 40 to 49 DAP) also met commercial requirements, although with a slight delay in the accumulation of SSC (FF from $4.42 \pm$ 0.52 to $4.27 \pm 0.33 \mathrm{~kg} \cdot \mathrm{cm}^{-2}$ and SSC from $9.64 \pm 1.14$ to $13.65 \pm 0.64{ }^{\circ}$ Brix, at $40-44$ and 45-49 DAP, respectively). At this time, 'MAK-10' fruits were netted with rinds turning to yellow, external signals of maturity that were also found in VED fruits. The fruits $\mathrm{kg} \cdot \mathrm{cm}^{-2}$ and SSC from $11.21 \pm 0.62$ to $13.08 \pm$ of 'MAK-10' collected after 50 DAP were not over ripened and still met commercial requirements for $\mathrm{FF}$ and $\mathrm{SSC}$, even having SSC values higher than those of the VED fruits (SSC $12.76 \pm 0.64{ }^{\circ}$ Brix vs. $15.68 \pm$ $0.32{ }^{\circ}$ Brix, for VED and 'MAK-10', respectively).

Differences in flesh properties were further studied by analyzing sugar and acid profiles in both lines during the ripening process. Both showed the typical profile of sugar evolution (Burger et al., 2006; Zhang et al., 2016), with the hexoses content, fructose and glucose, being almost constant during the ripening process and sucrose accumulation bursting during the last phase of ripening (Fig. 2). The differences between 'MAK-10' and VED resided in the higher sugar content of the IL, starting at 45-49 DAP and at 50 to 55 DAP for hexoses and sucrose levels, respectively. Consequently, sucrose equivalents, a variable directly linked with sweetness perception was considerably higher in 'MAK-10' by the end of the ripening process. Apart from the higher sugar content observed in 'MAK-10', this line exhibited a delay in the profile of sugar accumulation (Fig. 2). For example, VED tended to decrease hexoses content from 40 44 DAP, whereas this decrease started later (from 45 to 49 DAP) in 'MAK-10'. Similarly, the sucrose burst was delayed in 'MAK-10' (occurring from 35-39 to 45-49 in VED and from 45-49 to 50-55 in 'MAK-10').

The different performance in sugar accumulation did not apply to organic acid accumulation, as little differences could be found in the evolution of citric, malic, and glutamic acids between 'MAK-10' and VED (Fig. 3). In both lines, citric acid content more than doubled that of malic acid, whereas glutamic acid accumulated mainly at the end of the ripening process.
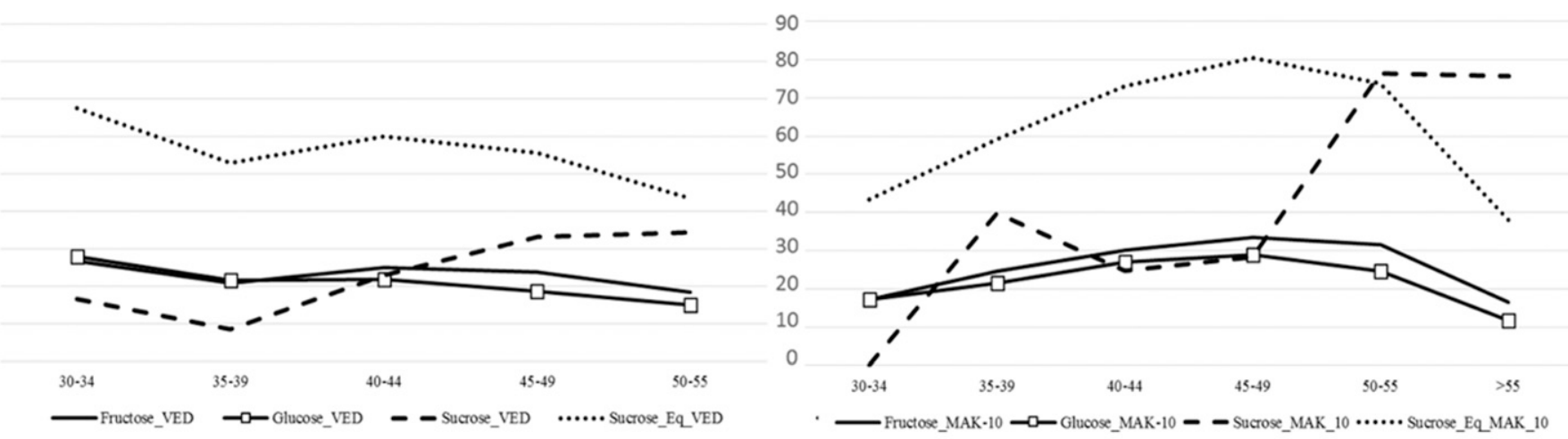

$\begin{array}{lcc}\text { 30-34 DAP } & \text { 35-39 DAP } & \text { 40-44 DAP } \\ \text { FR: ns } & \text { FR: ns } & \text { FR: ns } \\ \text { GL: P=0.04 } & \text { GL: ns } & \text { GL: ns } \\ \text { SC: } n s & \text { SC: } n s & \text { SC: ns } \\ \text { EQ: ns } & \text { EQ: ns } & \text { EQ: ns }\end{array}$

45-49 DAP

FR: $P<0.01$

GL: $P<0.01$

SC: $P<0.01$

EQ: $P=0.01$

\section{0-55 DAP}

FR: $P=0.01$

GL: $P=0.01$

SC: $P=0.03$

EQ: $P=0.01$

Fig. 2. Sugar components (g. $\mathrm{kg}^{-1}$ of fresh weight) at different days after pollination (DAP). Left: sugar components in 'Vedrantais' (VED) fruits. Right: sugar components in 'MAK-10' fruits. Bottom: analysis of variance $P$ values for the genotype effect for fructose (FR), glucose (GL), sucrose (SC), and sucrose equivalents at different DAP. NS = nonsignificant difference. 
The delayed ripening of 'MAK-10' could also be observed as a delay of flesh color change (Table 1). Fruits harvested at the immature state (30-34 DAP) still had green to yellow flesh color, whereas VED fruits were already light orange (FCa: $-4.95 \pm 0.76$ and $4.4 \pm 1.4 ; \mathrm{FCb}: 19.58 \pm 0.34$ and $21.7 \pm$ 0.48 , for MAK-10 and VED, respectively)
(Fig. 4). Despite this delay in color change, 'MAK-10' fruits did not differ from VED fruits at maturity (40-49 DAP) and even retained better flesh color when collected later at 50-55 DAP (FCa: $10.92 \pm 0.46$ vs. $6.84 \pm 0.78$, for 'MAK-10' and VED, respectively).

'MAK-10' and VED differ in the postharvest behavior. Despite the FF of
'MAK-10' fruits being constant while the fruits remained attached to the plant (Fig. 1), during storage it decreased slowly (Table 2), as it has been previously reported for Makuwa melons (Zhang et al., 2015). Nevertheless, 'MAK-10' fruits harvested at 40-44 DAP maintained a significantly higher $\mathrm{FF}$ than VED at $10 \mathrm{DAH}(2.05 \pm 0.05$ vs. $1.10 \pm 0.12$
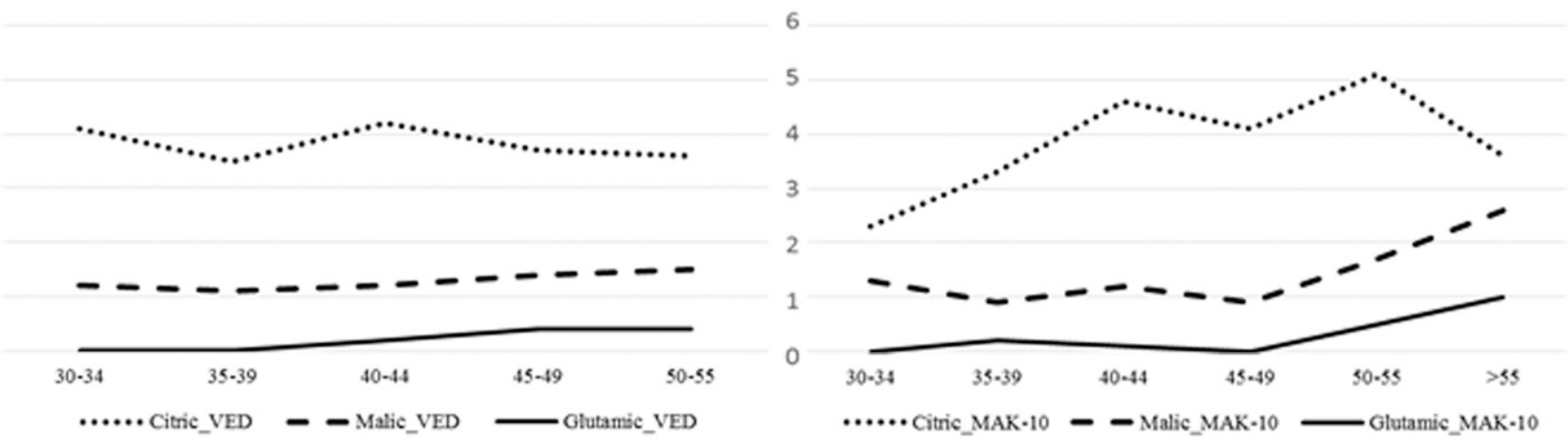

\begin{tabular}{|c|c|c|c|c|}
\hline 30-34 DAP & 35-39 DAP & 40-44 DAP & 45-49 DAP & 50-55 DAP \\
\hline CT: $P=0.03$ & CT: ns & CT: ns & CT: ns & $\mathrm{CT}: \mathrm{P}=0.01$ \\
\hline ML: ns & ML: ns & ML: ns & ML: $P=0.01$ & ML: ns \\
\hline GL: ns & GL: ns & GL: ns & GL: ns & GL: ns \\
\hline
\end{tabular}

Fig. 3. Principal organic acid components ( $\mathrm{g} \cdot \mathrm{kg}^{-1}$ of fresh weight) at different days after pollination (DAP). Left: organic acid components in 'Vedrantais' (VED) fruits. Right: organic acid components in 'MAK-10' fruits. Botom: analysis of variance $P$ values for the genotype effect for citric acid (CT), malic acid (ML), and glutamic acid at different DAP. NS = nonsignificant difference.

VED
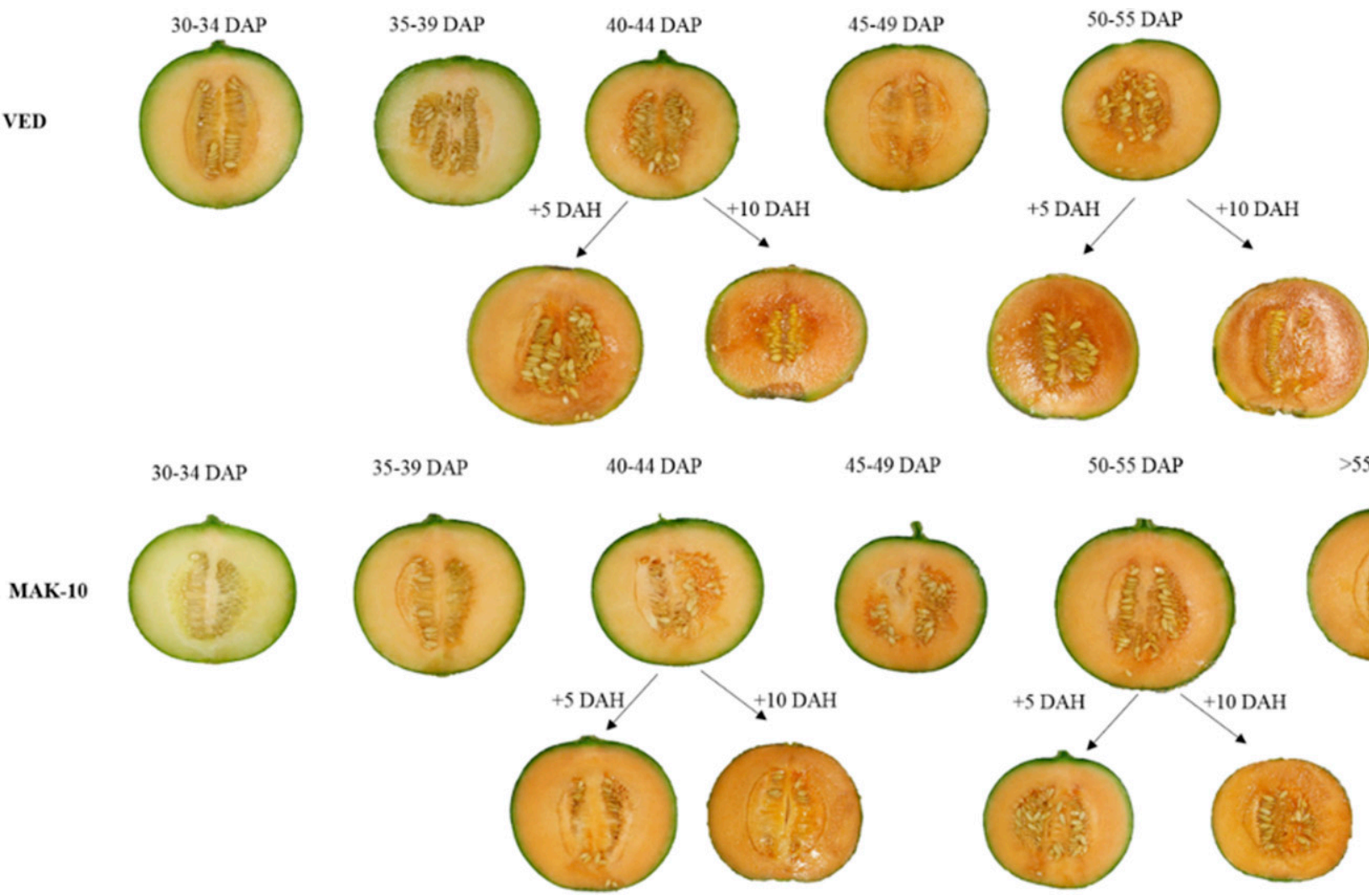

45-49 DAP

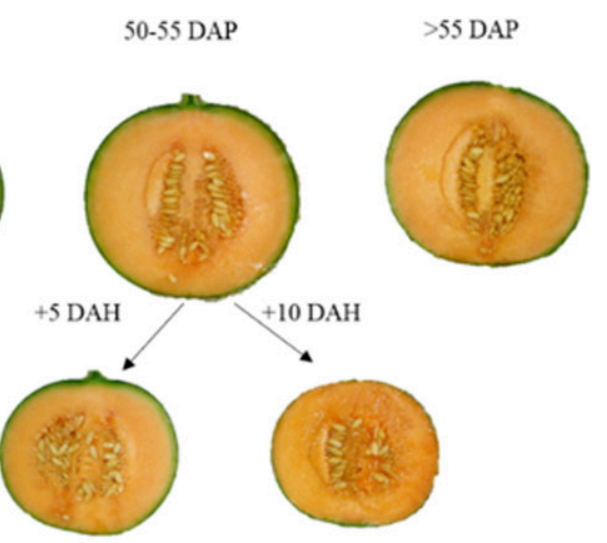

Fig. 4. Changes of 'Vedrantais' (VED) and 'MAK-10' fruits at different days after pollination (DAP) (30-34, 35-39, 40-40, 45-49, 50-55, and >55) and different days after harvest (DAH) (5 and $10 \mathrm{~d}$ of storage at room temperature). 
$\left.\mathrm{kg} \cdot \mathrm{cm}^{-2}\right)$. Similarly, 'MAK-10' fruits harvested at 50-55 DAP were firmer than VED fruits at 5 DAH $\left(1.45 \pm 0.05\right.$ vs. $\left.0.90 \pm 0.10 \mathrm{~kg} \cdot \mathrm{cm}^{-2}\right)$. In this case, VED fruits could not be analyzed at $10 \mathrm{DAH}$ because they were already rotten.

A decrease in SSC was observed during room storage (Table 2), more rapid in VED fruits collected at 40-44 DAP $(13.3 \pm 0.8$ and $9.8 \pm 0.9^{\circ} \mathrm{Brix}$, at 5 and $10 \mathrm{DAH}$, respectively) than in 'MAK-10' fruits (14.00 \pm 0.96 and $13.15 \pm 0.15^{\circ}$ Brix, respectively). 'MAK$10^{\prime}$ fruits collected at 50-55 DAP also had a stable Brix degree after 5 and $10 \mathrm{DAH}$ $\left(14.60 \pm 0.20\right.$ and $14.90 \pm 0.70^{\circ}$ Brix, respectively). These results do not disagree with those of Zhang et al. (2015), who described an initial increase in SSC in postharvest Makuwa fruits, reaching a maximum after $7 \mathrm{~d}$ of storage followed by a slow decrease.

VED and 'MAK-10' fruits differed in the postharvest evolution of hexoses content (Table 3), which presented a more accentuated decrease in VED than in 'MAK-10' fruits. This decrease, which specially affected glucose content, was consistent with the anticipation of hexoses decrease during the ripening process observed in VED fruits attached to plants. These differences were more marked in fruits harvested at 40-44 DAP (a harvesting time closer to commercial maturity of VED melons). Sucrose content increased during storage in both genotypes in fruits harvested at 40-44 DAP, more in VED than in 'MAK-10', consistently with the delay in sucrose burst previously observed in 'MAK-10' fruits at harvest (Fig. 2). In fruits harvested at 50-55 DAP, a similar slight decrease in sucrose content was observed for both genotypes during postharvest. Despite this reduction, the sucrose content in 'MAK-10' during postharvest was nearly twice that of the VED fruits (65.1-73.4 vs. $29.3-34.2 \mathrm{~g} \cdot \mathrm{kg}^{-1}$ in
'MAK-10' and VED fruits stored 5 and 10 $\mathrm{DAH}$, respectively).

These changes in sugar content resulted in a higher loss of sucrose equivalents in VED than in 'MAK-10', which was more pronounced in fruits harvested at 40-44 DAP (Table 3). Consequently, fruits of 'MAK-10' showed higher sucrose equivalents levels, which remained more stable during postharvest storage, and they had a higher potential in terms of sweetness perception. Previous studies with Makuwa melons have also reported reductions in hexoses and increase in sucrose contents during the postharvest storage (Liu et al., 2012).

Regarding the acid profile, citric acid slightly decreased in a similar way in both lines; whereas a different evolution was observed in glutamic and malic acid, mainly in fruits harvested at 40-44 DAP. Both acids increased in VED fruits during storage, but decreased or remained stable in 'MAK-10' fruits.

\section{Conclusions}

Our results indicate that the introgression from 'Ginsen makuwa' carried by 'MAK-10' clearly affects the ripening process, delaying flesh softening, flesh color change, and sugar accumulation, and preventing the formation of the AL and external volatiles emission in whole fruits. However, apart from the lack of $\mathrm{AL}$ and external aroma, the characteristics of the 'MAK-10' fruits at VED commercial maturity (40-49 DAP) are similar to that of the VED fruits. The 'MAK-10' line has the additional advantage that the fruits maintain commercial value for longer attached to the plant and have higher sugar content. This property could be useful to extend the harvesting period. 'MAK-10' fruits also retain
FF, sweetness, and have less variation of the organic acid profile for longer duration during room storage, which could be useful to extend the shelf life of Charentais melons. Despite the lack of external aroma, that could be a limitation for its use in specific markets, such as that of Cantaloupe Charentais, the flesh of 'MAK-10' fruits is aromatic. We did not find apparent differences in their internal aroma with VED fruits during fruit characterization. A quantitative analysis of flesh volatiles is being conducted to characterize the aromatic profile of this breeding line.

The Makuwa introgression of 'MAK-10' is located at chromosome 10. Therefore, the two genes, $A L-3$ and $A l-4$, reported to prevent the formation of AL by Perin et al. (2002) are not involved in this phenotype. This region contains two genes (MELO3C012390, annotated as NAC/NAM transcription factor, and MELO3C012332, annotated as a HD-Zip homeobox transcription factor) related with the ethylene transcriptional regulation (Ríos et al., 2017; Saladie et al., 2015). These genes are good candidates to be involved in the observed ripening delay. This ripening delay may also account for the observed differences in sugar content between VED and 'MAK-10'. Differences in sugar content in melon fruits can be due to differences in sugar accumulation and/or in sugar metabolism. In general, the increase in sucrose level is associated with a gradual decline in invertase activity and an increase in sucrose phosphate synthase activity, although contributions of additional enzymes have also been proposed. Several studies indicate that gene expression is reprogramed during the onset of ripening. According to Saladie et al. (2015), there exist differences between climacteric and nonclimacteric varieties in the expression of genes related to sugar metabolism,

Table 2. Mean and standard error of flesh firmness (FF) and soluble solids content (SSC) in fruits ${ }^{2}$ collected at 40-44 d after pollination (DAP) and at 50-55 DAP conserved at room temperature $5 / 10 \mathrm{~d}$ after harvesting (DAH).

\begin{tabular}{|c|c|c|c|c|c|c|c|c|}
\hline & \multicolumn{4}{|c|}{$\mathrm{FF}\left(\mathrm{kg} \cdot \mathrm{cm}^{-2}\right)$} & \multicolumn{4}{|c|}{ SSC $\left({ }^{\circ}\right.$ Brix $)$} \\
\hline & \multicolumn{2}{|c|}{ 'Vedrantais' (VED) } & \multicolumn{2}{|c|}{ 'MAK-10' } & \multicolumn{2}{|c|}{ VED } & \multicolumn{2}{|c|}{ 'MAK-10' } \\
\hline$\overline{40-44 \text { DAP + } 5 \text { DAH }}$ & $0.60 \mathrm{a}$ & 0.10 & $2.50 \mathrm{~b}$ & 1.00 & $13.30 \mathrm{a}$ & 0.80 & $14.00 \mathrm{a}$ & 0.96 \\
\hline 50-55 DAP + 5 DAH & $0.90 \mathrm{a}$ & 0.10 & $1.45 \mathrm{~b}$ & 0.05 & $12.65 \mathrm{a}$ & 0.55 & $14.60 \mathrm{a}$ & 0.20 \\
\hline $50-55 \mathrm{DAP}+10 \mathrm{DAH}$ & - & - & 1.00 & 0.00 & - & - & 14.90 & 0.70 \\
\hline
\end{tabular}

${ }^{\mathrm{z}}$ Six fruits of each DAP, DAH, and genotype were phenotyped except for VED fruits at 50-55 DAP + 10 DAH (rotten fruits were not analyzed). Mean values in a row (for each harvesting date) followed by the same letter are not significantly different based on the least significant difference test $(P \leq 0.05)$ between 'MAK10 ' and VED.

Table 3. Relative percentage of gain and loss of sugar compounds (fructose, glucose, sucrose, and sucrose equivalents) and acid compounds (citric, malic, and glutamic) of 'MAK-10' and 'Vedrantais' (VED) fruits ${ }^{2}$ harvested at different days after pollination (DAP) (40-44 and 50-55) and different days after pollination (DAH) (5 and 10) in comparison with fruits harvested at the same DAP without storage.

\begin{tabular}{llcccrrrr}
\hline DAP + DAH & Genotype & \% Fructose & \% Glucose & \% Sucrose & \% Sucrose eq & \% Citric & \% Malic & \% Glutamic \\
\hline $40-44+5$ & 'MAK-10' & 0.00 & -25.92 & 85.42 & -6.97 & -15.21 & -25.00 & 0.00 \\
& VED & -1.60 & -47.00 & 193.42 & -13.66 & -26.19 & 83.33 & 750.00 \\
$40-44+10$ & 'MAK-10' & 15.23 & 11.85 & -8.09 & 14.22 & -17.39 & -33.33 & -100.00 \\
& VED & -53.20 & -58.06 & 91.22 & -54.50 & -4.76 & 50.00 & 300.00 \\
$50-55+5$ & 'MAK-10' & -42.08 & -36.17 & -14.90 & -40.65 & -19.60 & -23.52 & 40.00 \\
& VED & -39.44 & -69.12 & -14.57 & -47.11 & -11.11 & -33.33 & 50.00 \\
$50-55+10$ & 'MAK-10' & -31.32 & -62.19 & -4.05 & -38.88 & 23.52 & -11.76 & 20.00 \\
& VED & -35.51 & -81.20 & 11.37 & -47.34 & 2.77 & -40.00 & -100.00 \\
\hline
\end{tabular}

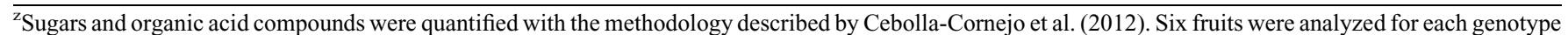
and DAP + DAH. 
suggesting that they may be potential determinants of sucrose content and postharvest stability of sucrose levels in fruit. After the autocatalytic ethylene synthesis, the sucrose levels are stable in the flesh of VED melons (from 45 to $49 \mathrm{~d}$ on), whereas sucrose levels continue rising in 'MAK-10'. Fruits of both genotypes were collected from plants at 50 $55 \mathrm{~d}$ (all still attached to the plant). However, whereas VED fruits had already started the climacteric ripening process that can stabilize sucrose content, 'MAK-10' fruits lacked the autocatalytic ethylene synthesis and continued accumulating sucrose. In addition, the presence in the introgression of MAK alleles of genes involved in sugar metabolism can contribute to this differential sucrose accumulation behavior. In the introgressed, genomic region also maps MELO3C012320, a Sucrose-P phosphatase 2 (CmSPP2) involved in sugar metabolism (Leida et al., 2015). This gene is a good candidate for future studies on this phenotype. Despite Makuwa melons being not as sweet as VED melons, MAK genes can have a different behavior when introgressed in a different genetic background. There are many examples of this type of masked variation when using ILs (Perpiñá et al., 2016).

In conclusion, 'MAK-10' provides fruits with long shelf life, stable flesh firmness, and high sugar content that can be suitable especially for melon markets other than Cantaloupe Charentais.

\section{Availability}

Small samples of 'MAK-10' seeds are available for research purposes, they can be obtained by written request to the author (mpicosi@btc.upv.es).

\section{Literature Cited}

Ayub, R., M. Guis, M. Ben Amor, L. Gilot, J.P. Rousant, A. Latché, M. Bouzayen, and J.C. Pech. 1996. Expression of ACC oxidase antisense gene inhibits ripening of cantaloupe melon fruits. Natl. Biotechnol. 14(7):862-866.

Burger, Y., U. Sa'ar, H.S. Paris, E. Lewinsohn, N. Katzir, Y. Tadmor, and A.A. Schaffer. 2006. Genetic variability for valuable fruit quality traits in Cucumis melo. Israel J. Plant Sci. 54(3): 233-242.

Cebolla-Cornejo, J., M. Valcárcel, J.M. HerreroMartínez, S. Roselló, and F. Nuez. 2012. High efficiency joint CZE determination of sugars and acids in vegetables and fruits. Electrophoresis 33(15):2416-2423.

Dahmani-Mardas, F., C. Troadec, A. Boualem, S. Leveque, A.A. Alsadon, A.A. Aldoss, C. Dogimont, and A. Bendahmane. 2010. Engineering melon plants with improved fruit shelf life using the TILLING approach. PLoS One 5(12):e15776.

Dai, N., S. Cohen, V. Portonoy, G. Tzuri, R. HarelBerja, M. Pompan-Lotan, N. Carmi, G. Zhang, A. Diber, S. Pollock, H. Karchi, Y. Yeselson, M. Petreikov, S. Shen, U. Sahar, R. Hovav, E. Lewinsohn, Y. Tadmor, D. Granot, R. Ophir, A. Sherman, Z. Fei, J. Giovannoni, Y. Burger, N. Katzir, and A.A. Schaffer. 2011. Metabolism of soluble sugars in developing melon fruit: A global transcriptional view of the metabolic transition to sucrose accumulation. Plant Mol. Biol. 76(1-2):1-18.

Esteras, C., F. Nuez, and B. Picó. 2012. Genetic diversity studies using molecular tools, p. 140 198. In: Y.H. Wang, T.K. Behera, and C. Kole (eds.). Cucurbits: Genetics, genomics and breeding of cucurbits. Science Publishers, New Hampshire.

Ezura, H. and W.O. Owino. 2008. Melon, an alternative model plant for elucidating fruit ripening. Plant Sci. 175(1-2):121-129.

Giovannoni, J.J. 2007. Fruit ripening mutants yield insights into ripening control. Curr. Opin. Plant Biol. 10(3):283-289.

Guo, X., J. Xu, X. Cui, H. Chen, and H. Qi. 2017. iTRAQ-based protein profiling and fruit quality changes at different development stages of oriental melon. BMC Plant Biol. 17:28.

Koehler, P.E. and S.J. Kays. 1991. Sweet potato flavor: Quantitative and qualitative assessment of optimum sweetness. J. Food Qual. 14(3): 241-249.

Leida, C., C. Moser, C. Esteras, R. Sulpice, J.E. Lunn, F. de Langen, A.J. Monforte, and B. Picó. 2015. Variability of candidate genes, genetic structure and association with sugar accumulation and climacteric behavior in a broad germplasm collection of melon ( $\mathrm{Cucu}$ mis melo L.). BMC Genet. 16:28.

Lin, Z., Y. Hong, M. Yin, C. Li, K. Zhang, and D. Grierson. 2008. A tomato HD-Zip homebox protein, LeHB-1, plays an important role in floral organogenesis and ripening. Plant J. 55(2):301-310.

Liu, W.W., H.Y. Qi, B.H. Xu, Y. Li, X.B. Tian, Y.Y. Jiang, X.F. Xu, and D.Q. Lv. 2012. Ethanol treatment inhibits internal ethylene concentrations and enhances ethyl ester production during storage of oriental sweet melons (Cucumis melo var. makuwa Makino). Postharvest Biol. Technol. 67:75-83.
Moreno, E., J.M. Obando, N. Dos-Santos, J.P. Fernández-Trujillo, A.J. Monforte, and J. Garcia-Mas. 2008. Candidate genes and QTLs for fruit ripening and softening in melon. Theor. Appl. Genet. 116(4):589-602.

Pech, J.C., M. Bouzayen, and A. Latché. 2008. Climacteric fruit ripening ethylene-dependent and independent regulation of ripening pathways in melon fruits. Plant Sci. 175(1):114 120.

Perin, C., M.C. Gómez-Jimenez, L. Hagen, C. Dogimont, J.C. Pech, A. Latché, M. Pitrat, and J.M. Lelièvre. 2002. Molecular and genetic characterization of a non-climacteric phenotype in melon reveals two loci conferring altered ethylene response in fruit. Plant Physiol. 129(1):300-309.

Perpiñá, G., C. Esteras, Y. Gibon, A.J. Monforte, and B. Picó. 2016. A new genomic library of melon introgression lines in a cantalupe genetic background for dissecting desirable agronomical traits. BMC Plant Biol. 16(1):154.

Pitrat, M. 2016. Melon genetic resources: Phenotypic diversity and horticultural taxonomy, $\mathrm{p}$. 1-36. In: R. Grumet, N. Katzir, and J. GarciaMas (eds.). Genetics and genomics of cucurbitaceae. Springer Science, New York, NY.

Ríos, P., J. Argyris, J. Vegas, C. Leida, M. Kenigswald, G. Tzuri, C. Troadec, A. Bendahmane, N. Katzir, B. Picó, A.J. Monforte, and J. Garcia-Mas. 2017. ETHQV6.3 is involved in melon climacteric fruit ripening and is encoded by a NAC domain transcription factor. Plant J. 91(4):671-683.

Rose, J.K.C., K.A. Hadfield, J.M. Labavitch, and A.B. Bennett. 1998. Temporal sequence of cell wall disassembly in rapidly ripening melon fruit. Plant Physiol. 117(2):345-361.

Saladie, M., J. Cañizares, M.A. Phillips, M. Rodriguez-Concepcion, C. Larrigaudiere, Y. Gibon, M. Stitt, J.E. Lunn, and J. Garcia-Mas. 2015. Comparative transcriptional profiling analysis of developing melon (Cucumis melo L.) fruit from climacteric and non-climacteric varieties. BMC Genomics 16:440.

Vegas, J., J. Garcia-Mas, and A.J. Monforte. 2013. Interaction between QTLs induces and advance in ethylene biosynthesis during melon fruit ripening. Theor. Appl. Genet. 126(6):15311544.

Zhang, C., Q. Shao, S.X. Cao, Y.F. Tang, J.Y. Liu, Y.Z. Jin, and H.Y. Qi. 2015. Effects of postharvest treatments on expression of three lipoxygenase genes in oriental melon (Cucumis melo var. makuwa Makino). Postharvest Biol. Technol. 110:229-238.

Zhang, H., H. Wang, H. Yi, W. Zhai, G. Wang, and Q. Fu. 2016. Transcriptome profiling of $\mathrm{Cucu}$ mis melo fruit development and ripening. Hort. Res. 3:16014. 